\title{
Paridad, elecciones y violencia: una discusión sobre los retos de las mujeres jóvenes indígenas
}

\author{
DOLORES FIGUEROA Y ALEJANDRA MENTADO BASILIO
}

\author{
Introducción
}

Electoral Parity, Democratic

Elections and Violence:

Discussing the Indigenous

Young Women's Challenges

DOLORES FIGUEROA

Centro de Investigaciones y Estudios Superiores en Antropología Social-

Ciudad de México, México dolores.figueroa@ciesas.edu.mx

Alejandra Mentado Basilio

Colectivo Tachi A'gú-Voz de Mujer, Zapotitlán Tablas, Guerrero, México mentadoale@gmail.com

Desacatos 59 , enero-abril 2019, pp. 172-183 n el proceso electoral de junio de 2018 se sucedieron muchos eventos sociopolíticos de gran interés, entre ellos, el triunfo de Andrés Manuel López Obrador como aspirante a la presidencia de la república y de muchos otros candidatos, hombres y mujeres, del partido Movimiento Regeneración Nacional (Morena) a una diversidad de cargos de gobierno. Sin embargo, estos acontecimientos con impacto nacional no son necesariamente representativos de lo acontecido en municipios indígenas y rurales. En lugares en los que la competencia por el poder está determinada por los criterios, intereses y usos de la política local, los escenarios de la participación electoral fueron complejos y peligrosos, sobre todo para candidatas jóvenes e indígenas, aun cuando fueran cobijadas por Morena. La paridad electoral, aplicada desde 2015, ha sido una de las medidas de acción positiva para la inclusión de mujeres de manera igualitaria en las candidaturas de los procesos de elección popular. Añadiría que esta iniciativa, diseñada para obligar a los partidos políticos a incluir mujeres en sus listas electorales y feminizar la democracia electoral, ha tenido como corolario la concatenación de violencias contra candidatas, nombrada de manera formal violencia política de género (Figueroa, 2017).

Queremos abrir la puerta para pensar en la participación electoral de mujeres indígenas con el testimonio preparado por Alejandra Mentado Basilio sobre su experiencia como candidata de Morena a la presidencia municipal de Zapotitlán Tablas, en la región de la Montaña de Guerrero, por efecto de la paridad de género. La lingüista indígena guerrerense obtuvo el Galardón Jóvenes que Inspiran 2017, en la categoría "Igualdad de género", otorgado por la organización de la sociedad civil Mukira para reconocer a jóvenes que han destacado por su labor a favor 
de los derechos humanos, justicia e igualdad, prevención de la violencia, liderazgo y empoderamiento de jóvenes, y cultura de la legalidad en el país.

$\mathrm{Al}$ igual que otros municipios de la zona, $\mathrm{Za}-$ potitlán está marcado por la pobreza extrema, en la que las violencias delincuenciales encuentran un caldo de cultivo perfecto. Las palabras de Mentado Basilio transmiten de manera reflexiva su vivencia del proceso, así como consideraciones sobre la complejidad de los escenarios de vulnerabilidad por los que transitó, en parte por efecto de la aplicación de la paridad electoral y también motivada por su aspiración personal de servicio. Su mirada revela de manera franca y acuciosa las formas de discriminación y violencia de género que operan en el campo de la política partidaria y comunitaria, y los estereotipos que condicionan de manera negativa la percepción de la gente sobre la capacidad de las mujeres para ejercer cargos de poder local. Una tendencia indica que las mujeres al frente de presidencias municipales son pocas (Barrera y Aguirre, 2003), lo cual habla de una reticencia social profunda para apoyarlas, por ser mujeres, y de lo peligroso y complejo que es para ellas hacer política en el clima de criminalidad $\mathrm{y}$ violencia que permea muchos territorios rurales $\mathrm{y}$ aislados del país (Guerrero, 2018).

Más allá de mencionar lo que ya sabemos sobre el funcionamiento de los órdenes de género en el mundo rural y la política local y partidista (Bonfil, 2003; Velásquez, 2003; Figueroa, 2017), en el testimonio de Alejandra queremos destacar la fuerza de su determinación y la entereza de su carácter para sobreponerse a situaciones de acoso, hostigamiento y amenaza de muerte. Ella rompe con claridad condicionamientos de clase y estereotipos étnico-genéricos por su formación profesional y la determinación de participar en escenarios públicos y comunitarios a los que la mayoría de las jóvenes indígenas de su generación no llegan. Reflexiona y reconoce con sinceridad que "era su momento de ser candidata", de abrir paso a posibilidades y experiencias nuevas que de otra manera nunca se hubieran logrado. En ella se aprecia cómo el ejercicio del liderazgo de mujeres indígenas y jóvenes toca de manera central las contradicciones del ejercicio de poder, como la verticalidad del liderazgo masculino versus el compromiso de servicio comunitario femenino. Las mujeres ejercen los cargos de manera consensuada, tienden más a negociar para convencer a propios y extraños de que las cosas pueden ser de otra manera. La vocación de Mentado Basilio se manifestó en la negociación, diálogo y encuentro con sabios, mayores, líderes, colaboradores y su familia cercana para asegurarse de hacer un trabajo digno y respetuoso, pero parece que no fue suficiente.

Algunos de los pensamientos, lecciones y recomendaciones que Alejandra vierte en este testimonio - escrito en Ahuixotitla, municipio de Zapotitlán Tablas, región Montaña, en agosto de 2018 - son de naturaleza práctica y estratégica; otros son materia de reflexión para el feminismo de la diversidad y la interseccionalidad de la política local, la masculinización de normas de participación en ámbitos comunitarios y los efectos de las medidas liberales de acción positiva a favor de la inclusión femenina. Ésta es una contribución valiosa a las consideraciones teóricas sobre el conocimiento vivencial de mujeres jóvenes indígenas profesionales y sus apuestas a futuro, pues reclaman un espacio de inclusión y presionan para reformular — desde adentro - las reglas de prestigio, participación y compromiso con y para la comunidad. De igual forma, ellas revelan los pasillos oscuros de la violencia contemporánea que tensa y trastoca los tejidos comunitarios y se ensaña contra los cuerpos femeninos para marcar y demarcar territorios con el poder de la criminalidad. 
Mi nombre es Alejandra Mentado Basilio, tengo 28 años de edad, soy hablante de la lengua mè'phàà $\mathrm{y}$ nací en la comunidad de Ayotoxtla, de donde es mi mamá. En la actualidad, radico en la comunidad de Ahuixotitla.

\section{¿Cuál fue mi motivación para participar en la contienda electoral?}

Desde que recuerdo, siempre ha sido complejo participar en los espacios públicos, principalmente para nosotras, las mujeres. En la mayoría de los casos, no tenemos oportunidades para obtener un cargo público como autoridad ni por voluntad ni por derecho. Existen excepciones con las compañeras que son madres solteras o viudas, a las que la comunidad asigna cargos religiosos de la mayordomía como una forma de castigarlas. A ellas les compete hacer aseos de la iglesia, llevar los santos a la procesión, regar flores; las obligan a recibir dinero de la iglesia para que el año siguiente entreguen el doble de la cantidad que hayan recibido, y dan de comer en las fiestas patronales. Estas compañeras se encuentran desprotegidas y violentadas por completo. Tienen doble función con sus hijos, ser padre y madre al mismo tiempo; tienen poco derecho a la toma de decisiones para recibir beneficios que por derecho les corresponden como ciudadanas de la comunidad, no tienen derecho a participar en las asambleas. El machismo que prevalece en estas comunidades es muy fuerte, sobre todo por los estereotipos que nos asignan los hombres: gritonas, altaneras, sin razón, sólo sirven en la cocina, sirven para procrear hijos, etcétera.

Crecí en un mundo en el que las mujeres pueden ser vendidas y los hijos pueden golpear a sus mamás, en el que hay hambre y no hay comida, tampoco derecho a la educación. Uno debe cuidar a los animales, trabajar y arreglar las carreteras para pedir dinero; si se logra obtener algo, hay que comprar huevo o chile. Recuerdo aquellos años en los que niños y niñas, cuando nos juntábamos para cuidar animales, nos peleábamos por el pasto, terreno, con mucho miedo. La violencia era tremenda, nos agarrábamos a golpes o pedradas, queríamos imitar a los adultos, cuando lo único que nos correspondía era jugar y estudiar. Me daba cuenta de que nosotras no podíamos ir a la escuela y que nos preparaban para la cocina, pues al final nos íbamos a casar, teníamos que levantarnos temprano para echar tortillas y preparar el atole.

Me daba cuenta de que mis tías y mi mamá todos los días eran violentadas, me ponía en medio; sin embargo, siempre era golpeada porque yo no quería vivir así, con miedo. Sabía que la postura era defenderlas, sin saber lo que eran los derechos humanos. Me regañaban por hacerlo. Una vez, un tío me golpeó mucho, sin piedad, por alzarle la voz y decirle que lo iba demandar, parecía que había cometido un pecado. Me golpeó tanto que ya ni recuerdo. A pesar de eso, yo le cuidaba su ganado.

Al terminar el Colegio de Bachilleres, en el plantel 10-A en Zapotitlán Tablas, me fui a estudiar la nueva licenciatura en desarrollo comunitario integral, en la Universidad Pedagógica Nacional, unidad 12, de Tlapa de Comonfort, que atiende de manera directa las necesidades de las comunidades originarias. El compromiso es regresar para trabajar con la gente y así fue. Como proyecto para mi titulación hice un diagnóstico comunitario en la comunidad de Ayotoxtla, municipio de Zapotitlán Tablas. Quise regresar a la comunidad de mi mamá. Después tuve la oportunidad de asistir a un foro sobre la participación ciudadana, llevado a cabo por la organización Incluye-t. Desde entonces comencé a indagar el tema del derecho de las mujeres a participar en puestos públicos. Poco a poco fui entendiendo que es importante y necesario involucrarse en los ámbitos político, comunitario y familiar. 
Todas tenemos el derecho de estar donde queremos estar, sin importar las barreras que nos pongan por ser mujeres. Pero todo tiene un costo, es muy difícil romper los estereotipos. La mayoría de los hombres de mi municipio no soportan que una mujer lleve el control de las actividades, sobre todo en la política, porque sienten que alguien los está dominando y se ponen en un plan de no querer obedecer. Hay que tener mucha paciencia, tolerancia, y saber que llevará un largo proceso para que ellos acepten que todos, hombres y mujeres, tenemos la capacidad para gobernar.

Por todos los obstáculos que enfrentamos como mujeres mè phàà, indígenas, decidí ser candidata a la presidencia municipal, para demostrar que somos capaces de ser dirigentes políticos en una zona con alto índice de violencia y feminicidios. Sabía que era muy arriesgado. Aun así, mantengo la postura de que alguna de nosotras debe poner un alto a esto, a veces hasta la vida arriesgamos. Hay infinidad de limitaciones que enfrentamos por querer participar en un puesto así.

Al aceptar la candidatura, me dije a mí misma que era el momento de ser la dirigente. A mí la paridad de género me favoreció, no iba a participar como candidata. Por lo general, este papel siempre se ha dado a los hombres. Yo sería coordinadora de campaña de un candidato del mismo partido. Quiero comentar que ya estaban seleccionados los precandidatos cuando llegó la paridad de género a mi municipio y esto desplazó a uno, se fue a otro partido porque no iba a tener la oportunidad de ser candidato a la presidencia municipal. Ésa fue la gran oportunidad de ser la portavoz de mis compañeras, mis tías, mi mamá, que por muchos años hemos sido aisladas y tenido poca participación. Esto fue algo repentino, aunque antes ya había pensado en participar en las elecciones, pero dicen que las cosas pasan cuando menos uno se lo espera.

En estas comunidades mè'phààs, ver a las mujeres participando es como salir del control: no es común. Por desgracia, seguimos siendo víctimas de estas acciones y tratos en los que los términos sexistas son altamente discriminatorios, siguen subestimando nuestras capacidades, inteligencia. A pesar de ello, nosotras combatimos el mundo de las burlas machistas. Hay muchas mujeres que no tuvieron la oportunidad de estudiar, mujeres participativas, pero no les dan la oportunidad, sino que las intimidan. Los municipios de la región de la Montaña presentan un alto índice de marginación. En mi municipio, Zapotitlán Tablas, 87.1\% de la población vive en extrema pobreza, de acuerdo con el Coneval (2018). Esto quiere decir que estamos en el olvido, la gente sufre de hambre, carece de salud, educación, vivienda, hay violencia y feminicidios. Tenemos muchas necesidades, no hay empleos, estamos en una situación problemática con la economía.

\section{¿Cómo llegué a ser candidata del Movimiento Regeneración Nacional?}

No estaba en mis planes participar como candidata. Lo había pensado un año antes, pero después tomé la decisión de trabajar poco a poco en la política, darme a conocer, ya estaba trabajando en dos comunidades de mi municipio con carencia económica, lo estaba haciendo. Y de pronto me proponen como candidata. La decisión fue muy fuerte. Primero tuve que consultar algunas amistades, también con mi familia. Para mí es muy importante escuchar las voces de los demás. Consulté a mis papás, a mis hermanos, a mi abuelo, que es una persona sabia, que conoce los problemas que enfrentamos, además es fundador de mi comunidad, Ahuixotitla.

También hice una reunión con las autoridades, los ex comisarios, los principales de la comunidad. Habíamos programado la reunión, dos días después acudimos al llamado, para mí fue un honor estar con ellos, para escucharlos. Desde luego, hubo varias opiniones, la idea era consultarles si era 
viable participar o no, y la respuesta fue favorable, así que acepté participar en la candidatura. Al ver esta situación, en mi opinión, las comunidades deben ser consultadas para sacar un candidato y después competir. El derecho a la consulta se ejerce muy poco. La mayoría de los candidatos se propone a sí mismo, como dice la gente de las comunidades: “¿en qué momento se propuso, que no supimos? Ahora llegan los que quieren y hasta los que menos pensamos". Yo no quise repetir lo mismo, siempre me ha gustado considerar a la gente, sobre todo en una situación como ésta. Una de las cosas que debemos tener presente cuando la gente se involucra o te propone es que no te dejarán sola, tendrás su respaldo, por eso es importante que participen, para involucrarlos en las actividades. Así fue como tomé la decisión de participar en esta contienda electoral.

Los consejos que me dieron fueron: 1) comprender a la gente, considerar que algunos nos traicionarían y no todos se involucrarían; 2) atender a toda persona por igual, sin ninguna distinción; 3) invitar a los demás líderes para que participen en las actividades de las elecciones; 4) respetar a las personas de las comunidades, y 5) cuidar de mi persona y no llegar tan noche, por la condición delictiva que enfrenta el municipio.

\section{¿Cómo me sentí durante la campaña?}

En la campaña es donde te das cuenta de la realidad. Te deja muchas enseñanzas, te hace crecer como persona, te hace madurar en tus decisiones, porque la política no es cualquier cosa. Tienes que saber negociar ciertos puntos, y además, debes tener la capacidad de coordinar a los compañeros que te rodean. De cierta manera, eres tú la que dirige, la que está al frente en esta batalla. Es como ir a un movimiento de lucha, y si no sabes orientar, puede que llegue alguien y lleve el control. Es importante tener esta capacidad, entrenar a la gente para que sean buenos en convencer a los demás, sobre todo saber coordinar para poder caminar hacia una sola meta. Mantener la cabeza fría y un corazón fuerte, porque a veces llegan las amenazas de muerte, y si no estás preparada emocionalmente, esta situación te puede traumar.

En mi caso, en el arranque de campaña me llegó una amenaza de muerte. Se hizo el mitin, y al terminar el discurso, un hombre vestido de pantalón de mezclilla, con playera azul y con sombrero negro tejano, se acercó a mí, hizo que estaba tomado. Me saludó y de manera amable lo saludé, lo invité a comer con nosotros. En ese momento me dijo que no me conocía, tampoco me ubicaba, me comentó que en algún momento iba a platicar. Se tardó un poco, no logré escuchar todo lo que me decía por el ruido que había. Después tuve que atender a otras personas que pasaban a saludarme. De pronto, el hombre desapareció. En ese momento, un compañero del partido se acercó y me dijo: "Ale, traigo un recado para ti, me dice que ya te va cargar la chingada, 'me voy a chingar tu candidata"'. En ese instante las plantas de mis pies comenzaron sudar y sólo di las gracias por el aviso. También me comentaron que nos tenían rodeados, había gente desconocida alrededor del evento. Sentí que mi corazón comenzó a latir fuerte, veía a mi familia y a la gente que estaba conmigo, lo único que esperaba era el momento. Me di a mí misma la fuerza y me dije que pasara lo que pasara allí iba a estar, sin importar. Lo único que hice fue buscar dónde esconderme y tuve que estar calmada para seguir con el evento, preparada por si pasaba algo. Después, durante la campaña, nos perseguían a mi equipo y a mí. No nos dejaban. Siempre había una moto que circulaba y carros desconocidos que iban a pararse a las comunidades para intimidarnos. Una vez, el equipo fue perseguido por una moto, hasta dejarlos en la cabecera municipal. También iban personas desconocidas a pararse afuera de la casa de campaña para vigilar nuestros movimientos.

Subí a una comunidad muy violentada, a la que la gente extraña no puede entrar. Al comienzo de la 


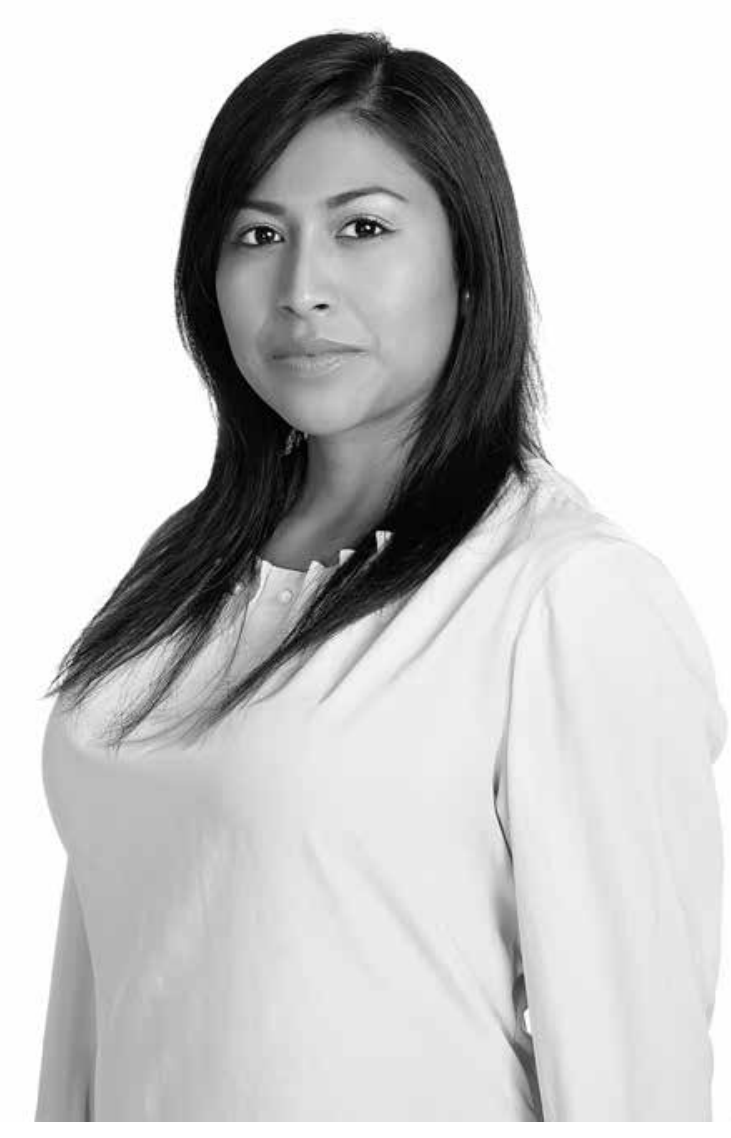

- Alejandra Mentado Basilio en campaña, mayo de 2018.

reunión con los pobladores, fue "el mero, mero", con su carro, sólo me vio, quiso intimidarme. No pasaron muchos días cuando una mujer fue asesinada con sus cinco hijos, acribillada y destrozada del rostro y la cabeza. Pocos días después, otros dos compañeros de otra comunidad fueron asesinados por "el mero, mero". Fue súper tensa la campaña, porque uno no podía movilizarse y por el temor de que en algún momento nos iban a caer a nosotros también.

Tuve que tomar medidas de seguridad, orientada por el Instituto Nacional Electoral (INE), que impartió un taller sobre herramientas para enfrentar la violencia política contra las candidatas. Lo bueno es que esto fue una semana antes de que empezara la campaña. Decidí dividir el equipo para la vigilancia y que no me dejaran sola, es decir, estuve acompañada siempre, pero también le encargué mi vida a mis compañeros, hombres y mujeres, para que pasara lo que pasara nos mantuviéramos unidos, porque la situación era demasiado fuerte.

En estos casos, hay que estar al tanto y no tener miedo a mandar. Muchas veces nos da pena pedir o solicitar algún apoyo porque hemos sido acostumbradas a que los hombres den órdenes; sin embargo, no necesitamos la autorización de ellos. En esta participación me di cuenta de que no necesitamos la autorización cuando ya estamos listas para tomar una decisión, sólo que no debemos tartamudear, debemos mostrar una postura fuerte, firme y segura, aunque por dentro nos estemos muriendo de las tensiones fuertes. No puedo negar que también llega un punto de estrés. Es tanta la adrenalina que circula en ese instante. A veces sólo quisieras que alguien te comprendiera y estuviera en tu lugar, pero no te puedes retractar, ya estás empezando un largo camino y no queda más que darle con todo, no doblegarse. Es algo que también es fuerte para nosotras, porque es un punto en el que la mujer debe mostrar que tiene capacidad, tener los pies bien puestos en la realidad.

En mi municipio fue difícil que comprendieran que la política que hacía con el equipo no era clientelismo. La gente está acostumbrada a aprovechar al máximo cada campaña y exprimir recursos económicos a los candidatos. La verdad, los pobladores no tienen piedad, están con "dame, si no, me voy con otro". En este punto sientes el estrés, porque si no cuentas con recurso económico la gente se va. Aquí es cuando se siente la impotencia de no poder hacer nada, porque hasta tu mejor amiga se va, es tan grande la ambición que parece que ya no importa nada. En la contienda electoral se demuestra quiénes son leales a ti, algunos se van y otros llegan con un gran espíritu, que dan la vida por ti.

Entiendo que uno no puede cambiar de la noche a la mañana la ideología de la gente. A veces 
somos muy inocentes al pensar que la gente siente igual que nosotros, a algunos no les importa el futuro sino el presente, y desde luego, algunos candidatos juegan con la pobreza que vivimos y es cuando entramos en conflicto por la diferencia de nuestras acciones. Es difícil que los pobladores comprendan esta política hasta que vean la realidad y hasta entonces aceptan. Algunos piensan que estamos locos. Algo claro debemos tener, si queremos mejorar nuestra condición de vida, es necesario empezar sin importar lo que digan los demás. Hay que demostrarlo.

Claro que no todo fueron tensiones, también estuve muy motivada, entusiasmada, porque estaba conociendo todas las comunidades de mi municipio. Estaba al 100\% con las comunidades y fue donde mostré mi liderazgo como mujer mè phàà, nacida en una comunidad y no en una cabecera. Siempre he sido amable, respetuosa, y este espacio me permitió comentarle a las personas de las comunidades lo orgullosa que estoy de hablar la lengua, que no me avergüenzo de quien soy, les digo que todos somos capaces de lograr lo que nos proponemos. Sé que existe mucha discriminación hacia nosotros y por eso algunos se avergüenzan de ser de una comunidad o de hablar la lengua. Era el momento indicado para reflexionar sobre nuestra identidad como pueblos originarios.

Me sentí muy apoyada, acompañada por mi familia y los de la comunidad. Mi familia me apoyó en todo: material, comida, emociones fuertes, consejos. En ese momento noté que estábamos unidos, con esto quiero decir que logramos muchas cosas. Mi mamá, mi papá, mis abuelos y mis tíos andaban de arriba para abajo trabajando conmigo, convenciendo a los compadres, amistades, etc. Fue una dinámica muy fuerte para ellos también.

En el arranque de campaña, acudieron personas que me apoyaron con la preparación de comida, los que estuvieron sirviendo el platillo, los que repartieron los refrescos, las tortillas. Mi abuelo y mi papá, cada uno donó una res para que comiera la gente. Ya en la campaña, hubo gente leal a mí que jamás pensé que estaría allí, me di cuenta de lo valiosa que soy para ellos y ellos para mí. También estuve apoyada por mis amistades que son de otros lugares, con mensajes de ánimo y algunas donaciones.

Fue un espacio lleno de emociones, conocer nueva gente, nuevas amistades, niños, adultos, jóvenes y abuelos. Fue la tensión más apasionada que había tenido en mi vida. Fue algo mágico y me siento muy feliz por ello. Me doy cuenta de que me gusta esta dinámica y estoy lista para la siguiente lección de la vida. Es aquí cuando uno valora más el tiempo $\mathrm{y}$ a las personas que te rodean.

\section{¿Cómo me arriesgué al postularme?}

Me gusta arriesgarme. Fue un honor participar y demostrarme a mí misma que soy capaz. Ser candidata es enfrentar de todo, las exigencias de la gente y la presión, es más grande de lo que te imaginas. Algunos te dirán que te van a apoyar y que van a estar contigo, pero al final te dejan en la batalla. Por eso no hay que creer todo lo que nos dicen los demás. Fui tan clara antes de aceptar la candidatura, en decir que no, porque no contaba con recurso económico y salió alguien que me dijo: "no te preocupes, yo te apoyo, tú solo ocúpate de la campaña y el discurso". Yo, despreocupada, me lo creí todo. Llegó el momento, sólo me daba mi avionazo, me decía: "no hay y nomás no hay”. Según la persona, buscaba el recurso, pero no llegaba con los resultados. Mi consejo es que, para poder ser candidata, uno debe prepararse económicamente, al menos para recorrer las comunidades. Fue muy frustrante el asunto de la movilidad. Tuve que acudir a otras amistades, a quienes yo menos pensaba, y allí estuvieron para apoyarme, estuvieron en la última batalla conmigo. Estoy muy agradecida con ellos. A pesar de toda la carencia que pasé, se logró lo que se logró. 
No me arrepiento de haber tomado la decisión. Fue la mejor de mi vida. Sentí la adrenalina. Lo más interesante es que toda la tensión que sientes se reduce a ese instante y es profunda. Puedo decir ahora que si tenemos la oportunidad de participar, ¡hay que hacerlo! Con o sin miedo y pase lo que pase. Siempre es bueno arriesgarse y sólo así uno puede vivir en carne propia las cosas.

\section{¿Comprender por qué no se ganó?}

Existen muchos factores. Quiero decir que gané independientemente de los resultados. Yo no compré votos ni tampoco regalé cosas. Me di cuenta de que para llegar a ser presidenta de mi municipio una debe tener millones de pesos y un buen padrino que pueda financiar. Sin más, esto es arriesgado. No sólo son tratos, sino riesgos de alto nivel. Además de arriesgar la vida, también se arriesga la familia, y esto causa mucha pena. Los factores principales que influyeron en este proceso de pérdida fueron:

\section{ECONÓMICO}

Voy a narrar algunas anécdotas que pasé durante la campaña. Primero, la gente no te tiene piedad y piensan que al estar en la política tienes dinero y no es así. Quizá otros partidos hayan creado un sistema clientelar. En ese caso, las personas llegaban a pedir dinero y decían: "nomás deme 8000 pesos". A pesar de que uno les explicaba la condición que padecía y decía que no contaba con esa cantidad, parecía que no entendían. Otra cosa, algunos amenazaban con irse a otros partidos. Les hacía reflexionar sobre el problema que enfrentamos en el municipio y el beneficio que teníamos con el plan municipal, pero poco caso hacían, es decir, no creían lo que les decías. Pedían dinero para las toreadas, bautizos, clausuras, grupo musicales, partos, zapatos y vestimenta, medicamentos, otros. Hubo candidatos que sí les llegaron al precio y les daban de todo. Lo interesante es que las mismas personas que venían conmigo, también iban con ellos. Hubo compañeros que les dieron dinero, calzado, mochilas, colchones, gramoxine para las hierbas, cubetas, despensas y muchas cosas más. En ese momento de campaña aparecieron todos esos regalos y todos eran amables, aparentaban lo que no son. La gente llegaba muy temprano a la oficina, como si les debieras algo. Es aquí cuando uno se da cuenta de la extrema pobreza que vivimos y que hace que los pobladores se preocupen sólo por aprovechar el instante preelectoral, porque saben que después de la elección se olvidarán de ellos y poco caso les harán. Es lamentable que la autoridad entre a saquear al municipio, a recuperar todo el dinero invertido y cambiar de mujer, que llegan a un precio de 300000 pesos, en lugar de preocuparse por un buen plan municipal.

Nadie piensa en bajar proyectos para la gente. Por eso estamos como estamos, con alto índice de violencia, sobre todo feminicidio. Durante la campaña asesinaron a una mujer con sus hijos. Lo más triste es que nadie dice nada y esto va creciendo cada día. En el municipio cada día se va agravando esta situación, además de extrema desnutrición, no hay productividad en el campo, la gente carece de comida, hay abuelos abandonados que no cuentan con vivienda, jóvenes sin dirección y sin empleo.

Estamos en una situación crítica, no hay una visión por mejorar al municipio. Tendremos que ser nosotros quienes estemos al frente para mejorar las condiciones, pero no creando clientelismo sino acción participativa. Seamos realistas, esto llevará un largo proceso.

\section{MACHISMO}

Durante la campaña me llegó un sinfín de comentarios sexistas. La gente cuestionaba si iba poder 


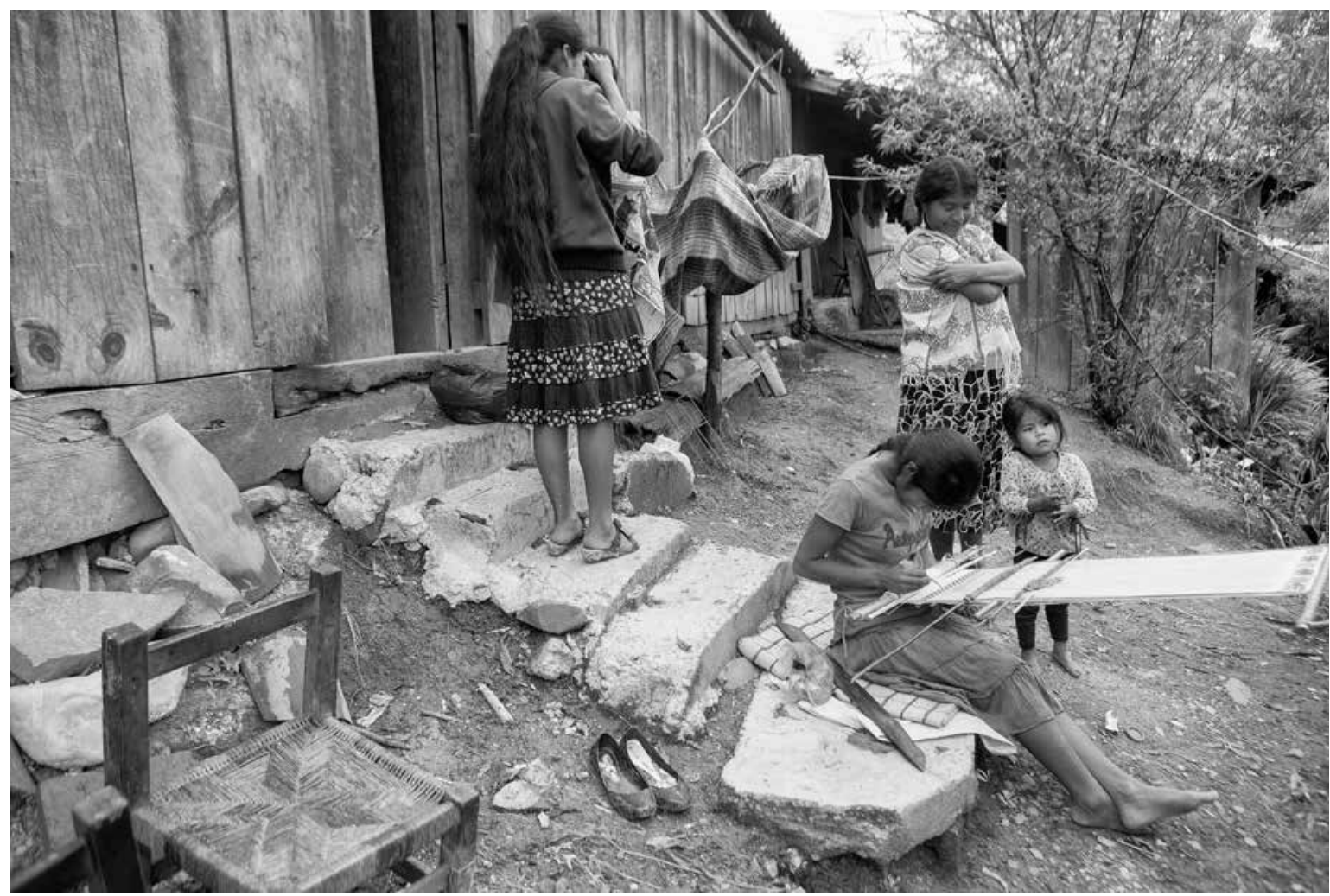

Prometeo LuCERo • Comunidad indígena tu'un savi, mixteca, en la Montaña de Guerrero, noviembre de 2015.

controlar el municipio, primero, por la edad - ser joven-, luego por el género — ser mujer y profesionista-. Llegué a una comunidad, una persona mayor se acercó a mí y lo primero que me dijo fue: “¿sí vas a poder llevar el control al municipio? Porque se necesita tener bien puesto el pantalón y un cinturón bien amarrado a la cintura". Llegaron otros comentarios que afirmaban que nosotras las mujeres teníamos que estar en la cocina y no participar en la política. Por otra parte, me di cuenta de los casos de otras candidatas. Les decían que no servían para hablar, que sus parejas las manipulaban y que tenían miedo, con infinidad de palabras sexistas. Fue fuerte la presión para nosotras. Incluso en mi caso, un compañero del mismo partido, que era precandidato, ya no logró ser el candidato por paridad de género. Antes de esto, noté que él no respetaba a los compañeros jóvenes, hombres y mujeres, no los escuchaba, él quería tener toda la razón. Cuando ya estábamos en la campaña, el compañero me condujo a hacer una reunión en la que el planteamiento era hacer alianza con una organización. Después de la reunión, se hizo un balance. El compañero se atrevió a ofenderme y dijo: "debiste ser más inteligente, tú que ya estás más preparada, debiste darles un discurso más fuerte, debiste impactarlos, convencerlos, según has estado formando líderes, dejaste que otros entraran hablar, etc.”. Comenzó a decir muchas cosas. En ese instante, trató de subestimarme ante el equipo; sin embargo, tuve valor de controlarme para no confrontarlo, primero porque no valía la pena, porque es una persona que no llega a la razón, así que de manera amable y respetuosa le dije que era la última vez que me levantaba la voz 
de esa manera y que no iba permitir que alguien me insultara. Aclaré también que de ninguna manera iba permitir que insultara a las compañeras, a nadie. Estaba temblando de enojo y él se había quedado con la boca abierta. Pensó que me iba manipular a su manera, con facilidad. Lo que puedo decir de esto es que a veces tenemos que poner un alto y todo tiene un límite.

El otro caso fue de un compañero que comenzó a gritarme en una reunión. Dijo que no había llevado nada, trató de hacerme quedar mal ante la gente, como si fuera un líder que hablaba por su comunidad, cuando sólo lo hacía para proteger a su candidato. La misma gente me defendió en ese momento. El compañero dijo: "si la candidata podrá gobernar, que lo demuestre con acción, que arregle la carretera primero y ahí vamos a demostrar que sí es capaz de hacer las cosas; que traiga una máquina y un volteo". Con una voz temerosa y enojada, pidió, además, que yo preparara la comida. La gente que me acompañaba dijo que no había problema en arreglar la carretera, pero que sí era necesario trabajar de manera colectiva. Acordamos el día y él nunca llegó a trabajar con nosotros, es decir, sólo alborotó pero no hizo nada. Son acciones que a veces nos someten y caemos en aceptar, por querer quedar bien con los demás, desde luego, demostrar que somos capaces. En sí, considero que no fue el momento adecuado.

\section{TIEMPO}

Una de las cosas que una persona debe considerar al estar en la política es el tiempo, saber coordinar bien y dividir. Al estar en la política se siente la presión de los segundos, se van volando, los minutos se convierten en oro. Otra de las recomendaciones para aquellos que tienen el deseo de participar como contendientes es que deben ir haciendo trayectoria, darse a conocer poco a poco, ir a las fiestas, reuniones, no deslindarse, hacer muchas amistades, conocer gente nueva.

Tener un buen equipo de trabajo implica una metodología didáctica que permita incluir a los miembros en las actividades, que tu equipo se vea obligado a hacer bien el trabajo, que participe de manera activa, con un cargo y responsabilidad. Desde luego, uno debe pedir resultados, porque cuando hay un descontrol no se puede avanzar y el tiempo se desvanece. Si uno no sabe de trabajo comunitario, es complicadísimo que se pueda lograr.

\section{¿Mi experiencia influyó de manera positiva en otras personas o en la comunidad?}

Mi participación como candidata a la presidencia municipal fue uno de los pasos más fuertes que he dado en la vida, a pesar de las condiciones, tuve el valor de enfrentar lo que venía. Vengo de un lugar en el que casi no hay participación de las mujeres, ya que en su mayoría se casan a temprana edad. He tenido el privilegio de contar con formación académica y he sido capaz de defender a las compañeras y estar con ellas en los momentos complicados. Como mujer, digo que es un gran ejemplo que me haya armado de valor para participar en esta contienda electoral, por ser de una comunidad marginada, discriminada, en la que la mayoría de las mujeres no estudia.

Ver esto en la comunidad es raro, pero que lo vean los niños, jóvenes, adolescentes, mujeres, es un gran logro. En la casa, con mis papás, mis hermanos y hermanas, mis tías, fue algo lindo y retador para mi vida. Dar el primer paso es lo más costoso, pero una vez que se abre esa brecha ya es un gran avance. Ver que sí podemos lograr, demostrar que somos capaces de coordinar el grupo político, tener el control del mando y ser una buena líder es lo más valioso. Por supuesto, hay que mantener la cabeza en alto y no doblegarse. Trabajar por un solo objetivo, mejorar las condiciones de vida y buscar alternativas para que 
ellos puedan darse cuenta de que existen muchas oportunidades que nos corresponden, independientemente de dónde estemos. Hay que descubrir la clave principal, lo que es la organización, llevar información, capacitarnos, día a día estar al pendiente de lo que ocurre para trabajar por la comunidad. Hacen falta muchas acciones para que se logre la igualdad de género, pero esto es poco a poco, la perseverancia es lo que dará un resultado positivo. Ya contribuimos a abrir este eco tan oscuro, que era un ataúd para las mujeres.

\section{¿Qué recomiendo a otras mujeres que pasan por una situación similar para salir adelante con éxito?}

- Tener buenos elementos en el equipo, gente con experiencia, que ya ha apoyado la campaña.

- Tener la capacidad de ser una buena líder o una buena coordinadora.

- Trabajar en equipo y considerarlos a todos.

- Tomar decisiones fuertes.

- Tener aliados externos e internos para que apoyen la campaña.

- Tener madurez política y una figura segura.

- Coordinar el trabajo en las comunidades y buscar gente leal.

- Mantener la cabeza firme y fría, no dudar.

- Estar segura de lo que queremos y no tambalear.

- Tener mucha confianza en nosotras mismas.

- No creer en todo y saber escuchar.

- Ser amable, no hablar de más y ser muy concreta en el discurso.

- Formar equipos de trabajo con enfoque de liderazgo: mujeres y hombres, jóvenes y adultos.
- Buscar gente mayor de cada comunidad, que tenga liderazgo, personajes pesados o figuras públicas, gente respetada.

- Tener mucha difusión en los medios de comunicación.

- Llevar gente a las reuniones, no andar sola, siempre acompañada.

- Hablar el idioma de los pobladores y ser muy sencilla, con humildad.

\section{¿Qué es la política comunitaria?}

Todos los días hacemos política, estar de acuerdo o no, tomar una decisión o no. La diferencia con la política comunitaria es que esté enfocada en las comunidades, en un contexto cultural, lingüístico y multidisciplinario. Los pobladores tienen sus formas propias de organizarse, sus usos y costumbres. Un político que quiera concentrarse en trabajar con los pueblos originarios debe conocer esta parte de la riqueza que poseen los integrantes, desde la familiar, la comunidad y las amistades.

La política es acción participativa y no sólo estar en un partido político. Estar en desacuerdo, hartos por todo lo que pasa, sin avance, ver un gobierno sin iniciativa, como en el caso de Zapotitlán Tablas. El gobierno que llega, lo primero que hace es comprar una mujer que será la otra esposa. Cuando se tiene la idea de buscar una alternativa, con proyectos de productos con enfoque sustentable, ahí comienza la política. Participar en un puesto político ya es otra cosa, es decir, ya es otro nivel, porque la figura cambia y en la toma de decisiones hay otra manera de ver las cosas. Es cuando uno entra en la dinámica de trabajar por el bien común y las propuestas deben incluir a toda la gente. D 


\section{Bibliografía}

Barrera Bassols, Dalia (ed.), 2008, I Encuentro estatal de presidentas municipales, sindicas y regidoras de los gobiernos municipales del estado de Guerrero, Grupo Interdisciplinario sobre Mujer, Trabajo y Pobreza/Secretaría de la Mujer del Estado de Guerrero, Chilpancingo.

Barrera Bassols, Dalia y Aguirre Pérez, Irma, 2003, "Participación de las mujeres en los gobiernos municipales de México”, en Dalia Barrera Bassols y Alejandra Massolo (comps.), Primer Encuentro Nacional de Presidentas Municipales. Memoria, Instituto Nacional de la Mujer, México, pp. 57-84.

Bonfil Sánchez, Paloma, 2003, “¿¿obedecer callando o mandar obedeciendo?”, en México Indígena, nueva época, vol. 2, núm. 5, pp. 6-14.

Bonfil Sánchez, Paloma, Dalia Barrera Bassols e Irma Aguirre, 2008, Los espacios conquistados. Participación política y liderazgo de las mujeres indígenas de México, Programa de las Naciones Unidas para el Desarrollo, México.

Consejo Nacional de Evaluación de las Política de Desarrollo Social (CONEVAL), 2018, "Informe anual sobre la situación de pobreza y rezago social. Zapotitlán Tablas, Guerrero". Consejo Nacional de Evaluación de las Política de Desarrollo Social, México. Disponible en línea: <https://www.gob.mx/cms/uploads/attachment/file/44893/Guerrero_072.pdf>. Consultado el 2 de agosto de 2018.

Figueroa Romero, Dolores, 2017, "Los caminos de la paridad, violencia política y la participación de mujeres indígenas en gobiernos locales en Guerrero", en Santiago Bastos y María Teresa Sierra (coords.), Pueblos indígenas y Estado en México. La disputa por la justicia y los derechos, Centro de Investigaciones y Estudios Superiores en Antropología Social (Colección México), México, pp. 32-59.

Guerrero Gutiérrez, Eduardo, 2018, "La segunda ola de violencia”, en Nexos, 1 de abril. Disponible en línea: <https://www.nexos.com. $m \times / ? p=36947>$.

Velásquez Cepeda, María Cristina, 2003, “¿Mujeres indígenas gobernando en municipios de Oaxaca?”, en México Indígena, nueva época, vol. 2, núm. 5, pp. 24-31. 